\title{
Pemanfaatan Batu Gunung Ambeso Pada Campuran AC-Base
}

\author{
Irpan $^{\star 1}$, Robert Mangontan ${ }^{* 2}$, Alpius ${ }^{\star 3}$ \\ *1 Mahasiswa Program Studi Teknik Sipil, Universitas Kristen Indonesia Paulus, Makassar, Indonesia \\ Irfahanstone20@gmail.com \\ *2,3 Dosen Program Studi Teknik Sipil, Universitas Kristen Indonesia Paulus, Makassar, Indonesia \\ robertm@ukipaulus.ac.id dan alpiusnini@gmail.com
}

\begin{abstract}
ABSTRAK
Penelitian ini dimaksudkan untuk pengujian karakteristik campuran AC-BASE yang menggunakan batu gunung Ambeso Metode dalam penelitian ini adalah melakukan serangkaian pengujian karakteristik agregat kasar, halus, dan filler kemudian merancang komposisi campuran AC-BASE serta pengujian Marshall untuk mendapatkan karakteristik campuran dan pengujian Marshall immertion untuk memperoleh indeks perendaman (IP) / Indeks kekeatan sisa (IKS)/ durabilitas campuran berkadar aspal optimum. Hasil penelitian yang dilakukan di laboratorium Jalan dan Aspal Fakultas Teknik Jurusan Sipil Universitas Kristen Indonesia Paulus Makassar, menunjukkan bahwa karakteristik bahan perkerasan berupa batu gunung ambeso kecamatan gandangbatu sillanan memenuhi spesifikasi sebagai bahan lapiasan perkerasan jalan. Melalui Uji Marshall diperoleh karakteristik campuran AC-BASE dengan kadar aspal 4,5\%, 5\%, 5,5\%,6\%, 6,5\%. Hasil pengujian Marshall immertion campuran Laston ACBASE dengan kadar aspal optimum 5\% diperoleh Indeks Perendaman (IP)/ Indeks Kekuatan Sisa (IKS)/Durabilitas sebesar 96,06\% memenuhi persyaratan yaitu minimal 90\%, memenuhi Spesifikasi Bina Marga Tahun 2018.
\end{abstract}

Kata Kunci : Karakteristik, Komposisi, Laston AC-BASE

\begin{abstract}
This research is intended for testing the characteristics of AC-BASE mixes using Ambeso volcano rock. The method in this study is to conduct a series of rough, fine, and filler aggregate characteristics test and then design an AC-BASE mixture composition and Marshall testing to obtain mixture characteristics and Marshall immertion tests for obtain immersion index (IP) / residual tightness index (IKS) / durability of the optimum asphalt mixture. The results of research conducted at the Road and Asphalt Laboratory of the Faculty of Civil Engineering, Indonesian Christian University Paulus Makassar, showed that the characteristics of pavement materials in the form of ambeso mountain stone, gandangbatu sillanan sub-district met specifications as road pavement coating materials. Through the Marshall Test obtained the characteristics of a mixture of AC-BASE with asphalt content of $4.5 \%, 5 \%, 5.5 \%, 6 \%, 6.5 \%$. The results of the Marshall immertion test of Laston AC-BASE mixture with optimum asphalt content of $5 \%$ obtained an Immersion Index (IP) / Residual Strength Index (IKS) / Durability of 96.06\% meeting the requirements of at least $90 \%$, meeting the 2018 Highways Specifications.
\end{abstract}

Keywords: Characteristics, Composition, Laston AC-BASE

\section{PENDAHULUAN}

Penggunaan agregat di Kabupaten Tana Toraja selama ini masih kurang maksimal diakibatkan karena kurangnya penelitian yang menunjukkan kualitas dari agregat tersebut. Mengingat melimpahnya agregat di Kecamatan Gandangbatu Sillanan, menjadi salah satu dasar bagi penulis untuk melakukan suatu penelitian. Oleh karena itu dalam penelitian batu gunung tersebut dimulai dari pengujian karakteristik material, perancangan komposisi campuran dan pengujian karakteristik campuran AC-BASE, sehingga dapat diketahui kualitas agregat yang digunakan dalam campuran tersebut.

Tujuan dari penelitian ini adalah untuk mengetahui karakteristik Batu Gunung Ambeso dari Kecamatan Gandangbatu Sillanan Kabupaten Tana Toraja dan
Aspal penetrasi 60/70 apakah memenuhi spesifikasi dan dapat digunakan sebagai campuran beraspal, mengetahui komposisi campuran AC - BASE berdasarkan Standar Bina Marga dengan menggunakan Batu Gunung Ambeso Kecamatan Gandangbatu Sillanan Kabupaten Tana Toraja. dan mengetahui nilai karakteristik campuran AC - BASE melalui pengujian marsall konvensional dan nilai indeks kekuatan sisa dengan metode pengujian marshall immersion.

Perkerasan jalan adalah bagian utama dari konstruksi jalan raya, kelancaran lalu lintas tergantung dari kondisi perkerasan jalan tersebut [1]. Bila perkerasan jalan bermasalah (rusak, berlubang, bergelombang, licin, retak) maka kelancaran lalu lintas akan terganggu baik dari segi waktu maupun biaya. Oleh karena itu, perkerasan jalan harus direncanakan 
sesuai kebutuhan serta kelas jalan berdasarkan jenis moda yang akan melalui. Perencanaan perkerasan jalan yang berhasil harus dilakukan dengan pertimbangan se-optimal mungkin sesuai dengan kebutuhan lalu lintas dan perkembangannya [2] [3]. Dalam perencanaan jalan, perkerasan terbagi atas 3 jenis perkerasan yang digunakan sesuai dengan kebutuhan, biaya, dan waktu. Perkembangan teknologi yang kian meningkat mendorong manusia agar dapat melakukan sesuatu secara cepat namun akurat. Perkerasan jalan selama ini dihitung dengan cara manual dan cukup menyita waktu.

Berdasarkan pengikat yang menyusunannya, konstruksi pekerja jalan yang digunakan pada penelitan ini adalah kostruksi perkersan lentur. Konstruksi perkerasan lentur (Flexible pavement) yaitu pekerjan yang mengunakan aspal sebagai bahan pengkait dimana lapisan - lapisan perkerasan memikul dan menyebarkan beban lalu lintas ketanah dasar [4].

Konstruksi perkerasan jalan yang saat ini berdasarkan bahan pengkaitnya adalah aspal dan dibedakan menjadi tiga yaitu Konstruksi perkerasan lentur (Flexible Pavement), merupakan lapisan yang di letakan diatas tanah dasar yang dipadatkan sedangkan konstruksi perkerasan kaku (Rigid Pavement), adalah jenis perkerasan yang menggunakan aspal, semen sebagai bahan utama dan perkerasan komposit merupakan perpaduan antara perkerasan kaku dan perkerasan lentur. Dimana perkerasan kaku (Rigid pavement) diletakan diatas perkerasan lentur. Perkerasan jalan dibuat berlapis-lapis bertujuan agar mampu menerima beban kendaraan yang melaluinya dan meneruskan kelaisan bawahnya.

Beton aspal adalah campuran antara agregat dengan aspal sebagai bahan pengikat dan semen sebagai bahan pengisi, serta bahan aditif yang dicampur, dihampar, dan dipadatkan dalam keadaan panas dengan suhu tertentu [5]. Pembuatan beton aspal dimaksudkan untuk mendapatkan suatu lapisan yang mampu menahan beban-beban yang bekerja di atasnya, serta berfungsi sebagai lapisan kedap air.

Beberapa penelitian terdahulu di antaranya Alpius meneliti Campuran HRS-WC Menggunakan Agregat Batu Gunung Desa Palipu Kecamatan Mengkendek Tana Toraja [6]. Rachman meneliti Pemanfaatan Batu Gunung Bottomale Toraja Utara sebagai Campuran Laston [7]. Fany meneliti Pemanfaatan Agregat Sungai Wanggar Kabupaten Nabire Sebagai Bahan Campuran AC-WC dan AC-BC [8].

\section{METODOLOGI PENELITIAN}

\section{Lokasi dan Waktu Penelitian}

Lokasi pengambilan material di Kecamatan Gandangbatu Sillanan Kecamatan Gandangbatu
Sillanan meliki Jarak dari tempat pengambilan agregat ke pusat kota sekitar $\pm 15 \mathrm{~km}$. material tersebut di bawah ke laboratorium UKI Paulus Makassar untuk diteliti.

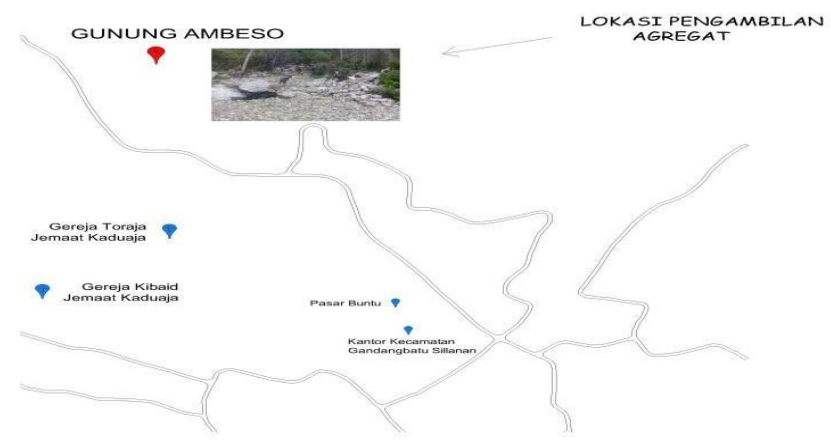

Gambar 1. Lokasi pengambilan material

\section{Pemeriksaan Karakteristik Bahan}

Perancangan dan pengujian karakteristik campuran beraspal harus mengikuti standar/spesifikasi yang ada. Untuk Indonesia, standar/spesifikasi yang digunakan adalah spesifikasi Umum Bina Marga 2018.

Rancangan pengujian didahului pengujian karakteristik bahan. Jika hasil pengujian tidak sesuai spesifikasi (berat jenis, keausan dan kelekatan) maka agregat tidak boleh digunakan juga jika karakteristik campuran tidak memenuhi spesifikasi maka campuran tersebut tidak boleh di produksi ( kecuali dilakukan modifikasi dengan bahan tambah) jika memenuhi spesifikasi maka dilanjutkan dengan rancangan campuran.

\section{a. Karakteristik agregat}

Standar rujukan/acuan pemeriksaan Analisa saringan agregat kasar dan agregat halus mengacu pada metode atau standar SNI ASTM C136:2012. Pemeriksaan berat jenis dan penyerapan agregat kasar mengacu pada standar rujukan SNI 1969:2016 dan Pemeriksaan berat jenis dan penyerapan air agregat halus mengacu pada standar rujukan SNI 1970:2016. Standar rujukan/acuan pemeriksaan kadar lumpur dan SE (Sand Equivalent) mengacu pada standar rujukan SNI 03-4428-1997. Pengujian Keausan (Abration) ini mengacu pada standar rujukan SNI 2417-2008. Pemeriksaan partikel kepipihan dan kelonjongan mengacu pada standar rujukan ASTM D - 4791-10 dengan perbandingan 1:5. Pemeriksaan agregat lolos ayakan No. 200 mengacu pada standar rujukan SNI ASTM C117:2012.

b. Karakteristik Aspal

Pengujian Penetrasi pada $25^{\circ} \mathrm{C}$ merujuk pada SNI 2456:2011; Pengujian Titik Nyala merujuk SNI 2433:2011; Pengujian Titik Lembek ( $\left.{ }^{\circ} \mathrm{C}\right)$ SNI2434;2011; Pengujian Berat Jenis SNI 2441:2011; Pengujian Daktilitas pada $2^{\circ} \mathrm{C}$ SNI 2432:2011; 
Pengujian Berat yang Hilang (\%) menggunakan SNI06-2441-1991.

\section{c. Komposisi Campuran}

Campuran beraspal menggunakan 3 (tiga) bahan utama yaitu agregat, aspal, dan filler. Untuk memenuhi karakteristik campuran beraspal, maka rancangan campran harus mengikuti spesifikasi Umum Bina Marga 2018.

\section{Teknik Analisis Data}

Dalam hal ini pengolahan data-data hasil survei dalam bentuk numerik dan akan dianalisis dengan rumus empirik statistika-matematis. Adapun tahapantahapan teknik analisis data dijelaskan sebagai berikut:

\section{a. Analisis Karakteristik Agregat}

Pada tahap ini dilakukan analisis karakteristik agregat dengan standar spesifikasi Bina Marga.

\section{b. Analisis Regresi}

Pada tahap ini dilakukan analisis regresi hubungan antara variabel yang menjadi karakteristik campuran.

\section{ANALISIS DAN PEMBAHASAN}

\section{Hubungan Kadar Aspal Terhadap Stabilitas}

Penggunaan kadar aspal yang sedikit dalam campuran AC-BASE akan menghasilkan selimut aspal yang tipis pada permukaan agregat yang mengakibatkan ikatan antar agregat menjadi lemah sehingga stabilitas campuran kecil, tetapi jika kadar aspal bertambah maka ikatan antar agregat menjadi kuat/stabilitas campuran menjadi besar. Hubungan kadar aspal dan stabilitas dapat dilihat pada Gambar 2.

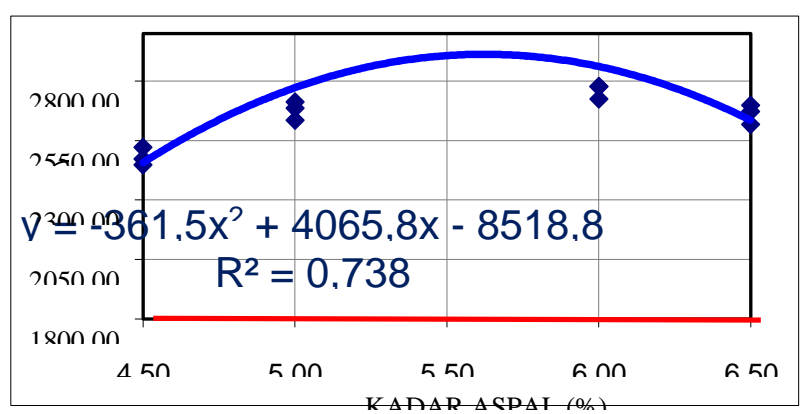

Gambar 2. Hubungan kadar aspal terhadap stabilitas

\section{Hubungan Kadar Aspal Terhadap VIM}

Semakin tinggi kadar aspal yang digunakan maka rongga dalam campuran akan banyak terisi aspal sehingga nilai VIM kecil begitu pula sebaliknya, apabila kadar aspal yang digunakan semakin kecil maka rongga dalam campuran banyak yang tidak terisi aspal sehingga nilai VIM akan semakin besar, kerena aspal berfungsi sebagai pengikat dan pengisi rongga campuran beraspal. Hubungan kadar aspal dan VIM dapat dilihat pada Gambar 3.

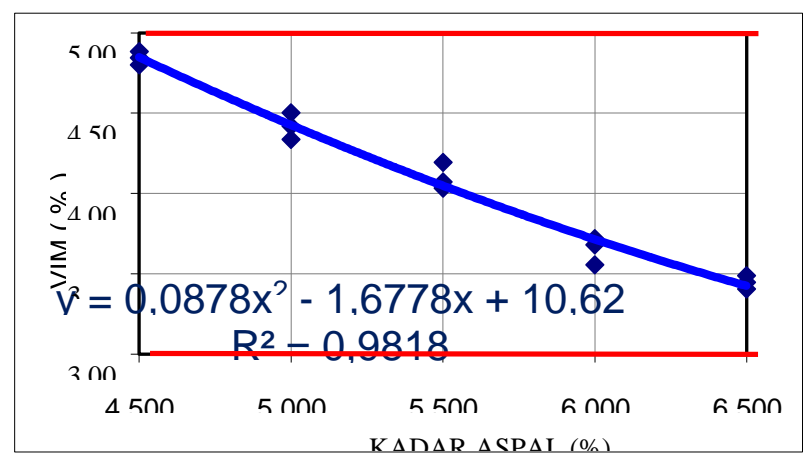

Gambar 3. Hubungan kadar aspal terhadap VIM

\section{Hubungan Kadar Aspal Terhadap Flow}

Penggunaan aspal dalam campuran beraspal kecil maka ikatan antar agregatnya berkurang yang menyebabkan kelenturan besar. Kekuatan campuran/stabilitas akan berbanding terbalik dengan kelenturan campuran/Flow. Hubungan kadar aspal dan flow dapat dilihat pada Gambar 4.

\section{Hubungan Kadar Aspal Terhadap VMA}

Semakin banyak aspal yang di gunakan maka rongga dalam agregat yang terisi aspal semakin besar sehingga nilai VMA akan meningkat. Hal ini dipengaruhi oleh penggunaan aspal yang banyak dimana saat pencampuran dan pemadatan, aspal akan menyelimuti agregat, mengisi rongga diantara agregat dan mengisi rongga dalam agregat. Hubungan kadar aspal dan VMA dapat dilihat pada Gambar 5.

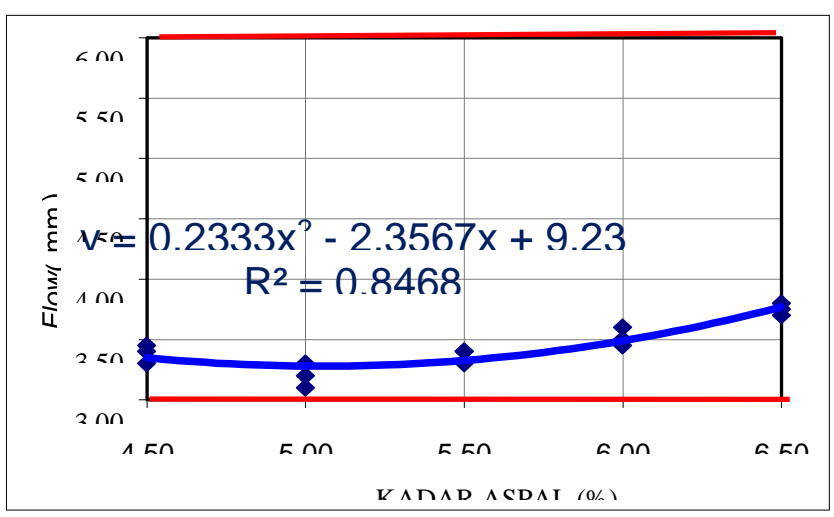

Gambar 4. Hubungan kadar aspal terhadap flow 


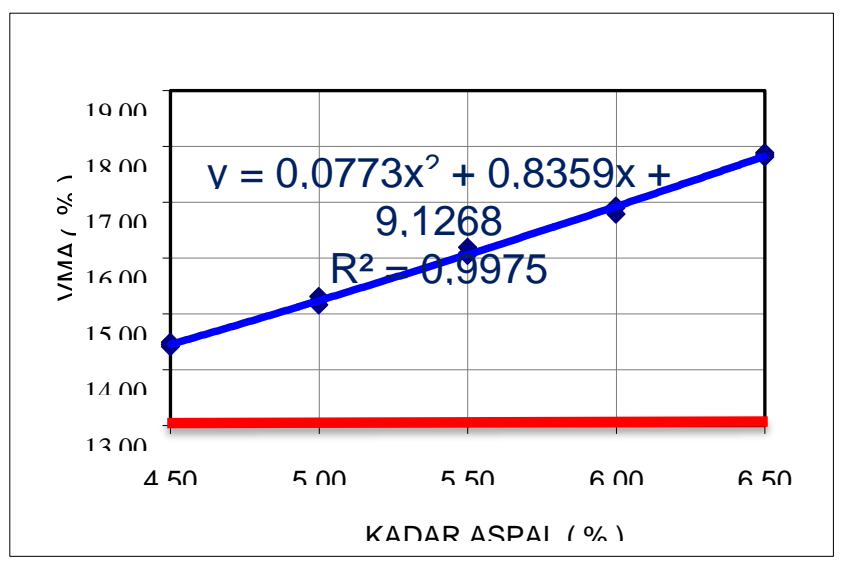

Gambar 5. Hubungan kadar aspal dan VMA

\section{Hubungan Kadar Aspal Terhadap VFB}

Penggunaan kadar aspal yang sedikit mengurangi VFB, penggunaan kadar aspal yang banyak memperbesar VFB. Di mana aspal dalam campuran akan mengisi semua rongga yang ada dalam campuran dan dalam agregat. Hubungan kadar aspal dan VFB dapat dilihat pada Gambar 6.

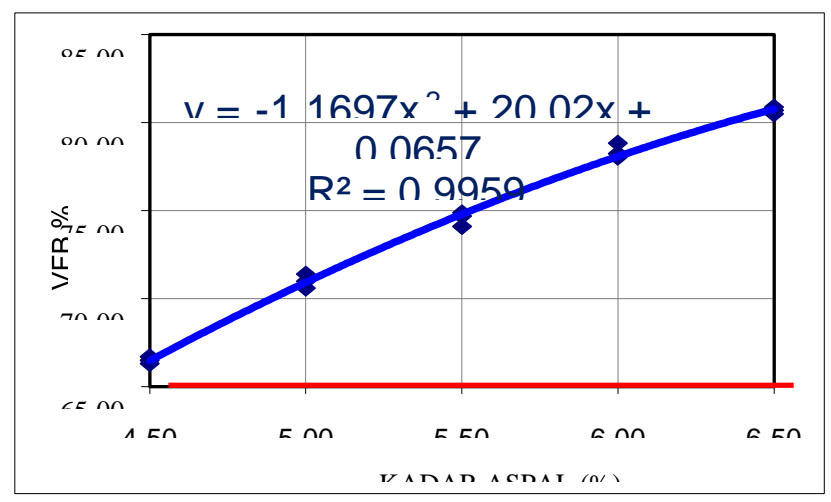

Gambar 6. Hubungan kadar aspal dan VFB

\section{Indeks Perendaman / Kekuatan Sisa}

Untuk mendapatkan nilai indeks perendaman/indeks kekuatan sisa dari campuran. adapun hasil pengujian indeks perendaman/indeks kekuatan sisa campuran, dapat dilihat pada Tabel 1. Indeks kekuatan sisi untuk rata-rata stabilitas Marshall Konvensional untuk kadar aspal 5\%, 3094,21 yaitu $97,50 \% ; 2123,44$ yaitu $98,29 \%$; dan 2141,91 yaitu $98,31 \%$.

Tabel 1. Indeks perendaman untuk AC-BASE

\begin{tabular}{ccc}
\hline PERSYARATAN & Min $\mathbf{9 0}$ & $\begin{array}{c}\text { INDEKS } \\
\text { KEKUATAN SISA / }\end{array}$ \\
\hline Kadar ASPAL $(\%)$ & Stabilitas & \\
\hline 5,50 & 3173,55 & \\
\hline 5,50 & 2160,37 \\
& 2178,83 \\
& & \\
\hline $\begin{array}{c}\text { Rata - Rata Stabilitas } \\
\text { Marshall Konvensional }\end{array}$ & 2504,25 & \\
\hline 5,50 & 3094,21 & 97,50 \\
\hline 5,50 & 2123,44 & 98,29 \\
\hline 5,50 & 2141,91 & 98,31 \\
\hline $\begin{array}{c}\text { Rata - Rata Marshall } \\
\text { Immertion }\end{array}$ & 2453,19 & $\mathbf{9 8 , 0 3}$ \\
\hline & & \\
\hline
\end{tabular}

\begin{tabular}{ll}
\hline INDEKS KEKUATAN & $\mathbf{9 7 , 9 6}$ \\
SISA / INDEKS & \\
PERENDAMAN $(\%)$ & \\
\hline
\end{tabular}

\section{Pembahasan}

Jika kadar aspal bertambah banyak lagi maka selimut aspal menjadi lebih tebal yang akan mengakibatkan ikatan antar agregat atau stabilitas campuran kembali menurun.

Penggunaan aspal yang banyak dalam campuran beraspal akan membantu mengisi rongga diantara agregat (dalam campuran).

Jika penggunaan aspal bertambah banyak maka ikatan antar agregat dalam campuran menjadi lebih kuat yang mengakibatkan kelenturan campuran menurun, kemudian jika penggunaan aspal bertambah banyak lagi maka selimut aspal menjadi lebih tebal yang mengakibatkan kekuatan campuran berkurang tetapi kelenturan bertambah besar.

Hasil pengujian karaktristik Campuran diperoleh untuk campuran AC-BASE melalui pengujian Marshall konvensional diperoleh karakteristik campuran beraspal yang memenuhi spesifikasi Bina marga 2018 yaitu, Stabilitas, Flow, VIM, VMA dan VFB.

\section{KESIMPULAN}

Karakteristik agregat yang berasal dari Kecamatan Gandangbatu Sillanan dan Aspal penetrasi 60/70 untuk campuran AC-BASE memenuhi Spesifikasi Bina Marga 2018 dan dapat digunakan sebagai campuran AC-BASE.

Adapun komposisi AC-BASE yaitu agregat kasar, agregat halus, filler dan aspal memenuhi Spesifikasi Bina Marga 2018.

Berdasarkan hasil pengujian karaktristik Campuran diperoleh untuk campuran AC-BASE melalui pengujian Marshall konvensional diperoleh karakteristik campuran beraspal yang memenuhi spesifikasi Bina marga 2018 yaitu, Stabilitas, Flow, VIM, VMA dan VFB.

\section{DAFTAR PUSTAKA}

[1] S. Hendarsin L., 2000, Perencanaan Teknik Jalan Raya. Bandung, Indonesia: Jurusan Teknik Sipil Politeknik Negeri Bandung.

[2] R. Krebs D. and R. Walker D., 1971, Highway Materials,. Michigan: McGraw-Hill, Universitas Michigan, 1971.

[3] D. N. Bunga, R. Rachman, and M. Selintung, 2019, "Effect of Collision Variation towards the Index Retained Strength of Mixed Asphalt Concrete Wearing Course," Int. J. Sci. Eng. Sci., vol. 3, no. 8, Art. no. 8, doi: 10.5281/zenodo.3408003.

[4] C. Kamba, 2013, "Pengaruh Penentuan Kadar Aspal Optimum Terhadap Kualitas Desain 
Campuran Beraspal," in Seminar Nasional Teknik Sipil UKIPaulus, Makassar, vol. 1, pp. 58 - 69.

[5] C. Kamba and R. Rachman, 2018, "Marshall Characteristics Test On Hot Rolled Sheet Base Combine Using Nickel Slag For Half Gap Graded," Int. J. Innov. Sci. Eng. Technol., vol. 5, no. 3, Art. no. 3.

[6] Alpius, 2019, "Campuran HRS-WC Menggunakan Agregat Batu Gunung Desa Palipu Kecamatan Mengkendek Tana Toraja," in Konferensi Nasional Teknik Sipil (KoNTekS) - 13, Banda Aceh, vol. 1, pp. 431-441.
[7] R. Rachman, 2020, "Pemanfaatan Batu Gunung Bottomale Toraja Utara sebagai Campuran Laston," J. Tek. Sipil Dan Teknol., vol. 6, no. 1, Art. no. 1.

[8] Fani. L. A, Irianto, Elizabeth, and Alpius, 2019, "Pemanfaatan Agregat Sungai Wanggar Kabupaten Nabire Sebagai Bahan Campuran ACWC dan AC-BC," Paulus Civ. Eng. J. Ojsukipaulusacid, vol. 1, no. 2, Art. no. 2 